\title{
SCIDOC
}

\author{
International Journal of Dentistry and Oral Science (IJDOS) \\ ISSN: 2377-8075
}

\section{Influence Of Suturing Techniques On Wound Healing Following Periodontal Flap Surgery}

Research Article

A Sankari Niveditha ${ }^{1}$, Arvina Rajasekar ${ }^{2 *}$

${ }^{1}$ Undergraduate Student, Saveetha Dental College and Hospitals, Saveetha Institute of Medical and Technical Sciences (SIMATS), Saveetha University, Chennai- 77, India.

${ }^{2}$ Senior Lecturer, Department of Periodontics, Saveetha Dental College and Hospitals, Saveetha Institute of Medical and Technical Sciences [SIMATS], Saveetha University, Chennai- 77, India.

\section{Abstract}

Background: Proper suturing technique is essential for obtaining wound healing and avoiding infection. Techniques that must be mastered include good version, maintaining uniform tensile strength and precise approximation along tissue edges. The primary objective of suturing is to position and secure surgical flaps to promote optimal healing.

Aim: The aim of the study was to evaluate the influence of two different suturing techniques on wound healing following periodontal flap surgery.

Materials And Methods: The single centered cross-sectional study was conducted among 100 patients who had undergone periodontal flap surgery in the Department of Periodontics, Saveetha Dental College and Hospitals, Chennai, India. The patients were categorized based on the suturing technique as follows: Group 1: Mattress (50 patients), Group 2: Direct loop (50 patients). After one week of periodontal flap surgery, all the patients were recalled for suture removal. After suture removal, the healing index score was recorded for both the groups and compared. The data was analyzed using Statistical Package for Social Sciences (SPSS Software, Version 23.0). Frequency, percentage and Chi-square test were calculated.

Results: Majority of the patients with mattress suturing technique $(28 \%)$ had better wound healing when compared to the patients with direct loop suturing technique $(21 \%)$. The association between type of suturing technique and wound healing index was done by Chi square test and was found to be significant with the p value of 0.05

Conclusion: The present study suggests that better wound healing was observed among patients with mattress suturing technique when compared to direct loop suturing technique following periodontal flap surgery.

Keywords: Direct Loop Suture; Mattress Suture; Suturing Technique; Innovative Technique; Wound Healing.

\section{Introduction}

Periodontitis is a chronic inflammatory disease which affects the supporting structures of the tooth. The main etiology of the disease is dental plaque, however the disease gets aggravated by various risk factors including age, gender, smoking, stress, socioeconomic status, genetic factors, systemic diseases and hormonal changes[1-9]. If the condition is left untreated it leads to increase in pocket depth, gingival recession, clinical attachment loss, bone loss, furcation involvement, pathological migration and tooth mobility eventually leads to tooth loss [10-15].
The management of periodontitis involves scaling and root planning followed by flap surgery. In periodontal surgery, the most common method of wound closure is by sutures [16]. Proper suturing technique is essential for obtaining wound healing and avoiding infection. Techniques that must be mastered include good version, maintaining uniform tensile strength and precise approximation along tissue edges [17]. The primary objective of suturing is to position and secure surgical flaps to promote optimal healing. The ideal suture is strong, handles easily, and forms secure knots [18]. Periodontal surgery incorporates many issues and is complicated in many cases as it deals with the periodontal disease process affecting both soft and hard tissues [19]. Flap sta-

*Corresponding Author:

Dr. Arvina Rajasekar,

Senior Lecturer, Department of Periodontics, Saveetha Dental College and Hospitals, Saveetha Institute of Medical and Technical Sciences [SIMATS], Saveetha University, Chennai- 77 , India.

Tel: +919486442309

E-mail: arvinar.sdc@saveetha.com

Received: September 13, 2021

Accepted: September 22, 202

Published: September 23, 2021

Citation: A Sankari Niveditha, Arvina Rajasekar. Influence Of Suturing Techniques On Wound Healing Following Periodontal Flap Surgery. Int J Dentistry Oral Sci. 2021;8(9):46114614. doi: http://dx.doi.org/10.19070/2377-8075-21000939

Copyright: Dr. Arvina Rajasekar ${ }^{\circ} 2021$. This is an open-access article distributed under the terms of the Creative Commons Attribution License, which permits unrestricted use, distribution and reproduction in any medium, provided the original author and source are credited. 
bility and durability is the major concern during the postoperative period [20]. The mouth is a moist, movable and contaminated environment where healing has to take place following a periodontal surgery [21]. At the same time basic functions such as eating and speaking should be accomplished. Many patients may also be involved in destructive behaviours such as smoking or poor oral hygiene or poor oral hygiene, which has an impact on surgical efforts [22].

Suturing is often the most tedious part of any surgical procedure. However, applying the basic principles and techniques of suturing can help make suturing more efficient and can also improve the wound healing of surgery [23]. Wound healing after periodontal flap surgery also depends on the technique employed. Various suturing methods are being practised in the field of periodontal surgery. Commonly used suturing techniques are simple interrupted suturing techniques, continuous suturing techniques and vertical or horizontal mattress suturing techniques for adequate approximation of the elevated flap [24]. Mattress suturing techniques are employed in the areas where tension free closure cannot be accomplished. It is used to resist muscle pull, evert the wound edges which keeps the epithelium away from underlying structures and to adapt the tissue flap tightly to the underlying structures in case of flap surgery, bone graft, tissue graft, alveolar ridge corrections, regenerative membrane or dental implant. Mattress suturing techniques are helpful in close approximation of the flap under tension and in the cases of suturing done in different planes [25]. The direct loop or the interrupted suture are most commonly used suture in periodontal surgery and is frequently used to affix tension-free and mobile surgical flap [17].

Our team has extensive knowledge and research experience that has translated into high quality publications [26-45]. Through extensive literature search, it was revealed that there is a lack of adequate studies assessing the influence of suturing techniques on wound healing following periodontal flap surgery. Hence, the rationale of this study was to evaluate the influence of two different suturing techniques on wound healing following periodontal flap surgery.

\section{Materials and Methods}

The single centered cross-sectional study was conducted among
100 patients who had undergone periodontal flap surgery in the Department of Periodontics, Saveetha Dental College and Hospitals, Chennai, India. The ethical clearance was obtained from the Institutional Ethical Committee and a written informed consent was obtained from all the study participants.

The patients were categorized based on the suturing technique as follows: Group 1: Mattress (50 patients), Group 2: Direct loop (50 patients). After one week of periodontal flap surgery, all the patients were recalled for suture removal. After suture removal, healing index score based on Huang et al., 2005 Wound Healing Index [46] was given for all the patients.

\section{Statistical Analysis:}

The data was analyzed using Statistical Package for Social Sciences (SPSS Software, Version 23.0). Descriptive and inferential statistics were done for data summarization and presentation. Frequency, percentage and Chi-square test were calculated.

\section{Results}

A total of 100 patients were enrolled. Of which 50 patients had undergone periodontal flap surgery with mattress suturing technique and another 50 patients had undergone periodontal flap surgery with direct loop suturing technique. Wound healing index (WHI) scores were recorded and compared between both the groups.

Among 50 patients with mattress suturing technique, 28 patients showed wound healing index score of 1,17 patients showed wound healing index score of 2 and 5 patients showed wound healing index score of 3 . Among 50 patients with direct loop suturing technique, 21 patients showed WHI score of 1,18 patients showed WHI score of 2 and 11 patients showed WHI score of 3 . Majority of the patients with mattress suturing technique had better wound healing when compared with the patients with direct loop suture technique. The association between type of suturing technique and wound healing index was done by Chi square test and was found to be significant with the $\mathrm{p}$ value of 0.05 (Figure $1)$.

Figure 1. The bar chart represents the association between suturing technique and wound healing index (WHI). $\mathrm{X}$ axis represents different suturing techniques and $\mathrm{Y}$ axis represents the percentage of patients who underwent periodontal flap surgery. Blue colour denotes wound healing index score of 1(WHI-1) and green colour denotes wound healing index score of 2 (WHI-2) and yellow colour denotes wound healing index score of 3 (WHI-3). Majority of the patients with mattress suturing technique $(28 \%)$ had better wound healing when compared to the patients with direct loop suturing technique (21\%). The association between type of suturing technique and wound healing index was done by Chi square test and was found to be significant with the p value of 0.05 .

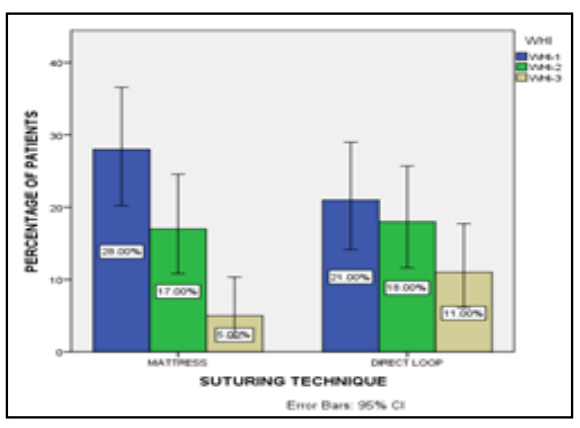




\section{Discussion}

The present study was done to evaluate the influence of two different suturing techniques on wound healing following periodontal flap surgery.

From the present study, it was noted that mattress suturing had better wound healing than the direct loop suturing among the patients who had undergone periodontal flap surgery. Kumar et al conducted a study to compare the mattress suture and simple loop interrupted suture following modified Widman flap surgery and found out that flap closure by modified vertical internal mattress suturing technique resulted in better improvement than the simple loop interrupted sutures [47].

Gopu et al., in 2012 conducted a study to assess the efficacy of modified vertical mattress suturing technique for flap approximation after periodontal flap surgery. In this study the modified vertical mattress suturing technique was found to be reliable and an effective method of suturing for flap approximation [48]. Another study was conducted to evaluate whether horizontal mattress suturing is more effective than simple interrupted suturing on postoperative complication and primary wound healing after impacted mandibular third molar surgery. There was significantly less wound dehiscence in the horizontal mattress suturing than in the simple interrupted suturing technique. According to the results of this study, the horizontal mattress suturing technique is more effective than the simple interrupted suturing technique on wound healing [49].

Similarly, another study was done to assess the influence of suturing technique on marginal flap stability following coronally advanced flap. In this study simple interrupted, single sling or sling and tag suture techniques were investigated through a specific tool involving a load cell- based recording device. Suturing technique highly affects the marginal flap stability following coronally advanced flap and the technique was shown to be a positive predictor for flap stability [50].

According to Christopher et al, the mattress suture technique is the most commonly used effective suturing technique and it prevents early wound dehiscence [57]. Our results are in accordance with the previous study. This might be because of the advantage of mattress suturing technique, as it reduces dead space between the flap and the bone as compared to other suturing techniques promoting better improvement.

The limitation of the study was that only two different suturing techniques were included in the study. However this study would shed light for future studies assessing the influence of other types of suturing techniques, different suturing materials, surgical procedure and patient related factors on wound healing.

\section{Conclusion}

The present study suggests that better wound healing was observed among patients with mattress suturing technique when compared to direct loop suturing technique following periodontal flap surgery.

\section{Acknowledgement}

The author would like to acknowledge the help and support rendered by Saveetha Dental College and Hospitals, Saveetha Institute of Medical and Technical Sciences, Saveetha University, Chennai.

\section{Funding}

The present study is funded by

- Saveetha Institute of Medical and Technical Sciences

- Saveetha Dental College and Hospitals

- Saveetha University

- $\quad$ Ti Megah Sdn Bhd, Malaysia

\section{References}

[1]. S TA, Thanish AS, Rajasekar A, Mathew MG. Assessment of tooth loss in chronic periodontitis patients with and without diabetes mellitus: A crosssectional study. Int. j. res. pharm. sci. 2020;11:1927-31.

[2]. B G, Geethika B, Rajasekar A, Chaudary M. Comparison of periodontal status among pregnant and non-pregnant women. Int. j. res. pharm. sci. 2020;11: 1923-6.

[3]. Rajasekar A, Lecturer S, Department of Periodontics, Saveetha Dental College and Hospitals, Saveetha Institute of Medical and Technical Sciences, Saveetha University, et al. Assessment Of Periodontal Status among Post Menopausal Women: A Retrospective Study. Int. J. Dent. Oral Sci. 2020. p. 1063-6.

[4]. Kandhan TS, Rajasekar A. Prevalence of Periodontal Diseases Among Patients with And Without Systemic Diseases-A Retrospective Study. J. Complement. Med. Res.2020;11(4):155-62.

[5]. Assessment of periodontal health among patients with diabetes mellitus: a retrospective study. J. contemp. issues bus. gov. 2021,26.

[6]. SHAH P, RAJASEKAR A, CHAUDHARY M. Assessment of Gender Based Difference in Occurrence of Periodontal Diseases: A Retrospective Study. J. contemp. issues bus. gov. 2021 Feb 16;27(2):521-6.

[7]. MOHD AZLAN SUNIL NS, RAJASEKAR A, DURAISAMY R. Evaluation of Periodontal Health Adjacent to Class V Restoration. J. contemp. issues bus. gov. $2021 \mathrm{Feb}$ 15;27(2):324-9.

[8]. RAJASEKAR A, CHAUDARY M. Prevalence of Periodontal Diseases Among Individuals Above 45 Years: A Retrospective Study. J. contemp. issues bus. gov. $2021 \mathrm{Feb}$ 19;27(2):527-33.

[9]. Rajasekar A, Mathew MG. Prevalence of Periodontal Disease among Individuals between 18-30 Years of Age: A Retrospective Study. Ann Med Health Sci Res. 2021 Jun 30.

[10]. Rajeshwaran N, Rajasekar A, Kaarthikeyan G. Prevalence of Pathologic Migration in Patients with Periodontitis: A Retrospective Analysis. J. Complement. Med. Res. 2020;11(4):172-8.

[11]. KARTHIKEYAN MURTHYKUMAR DR, KAARTHIKEYAN DG. Prevalence of Tooth Loss Among Chronic Periodontitis Patients-A Retrospective Study. Int. J. Pharm. Res. 2020 Jul;12(2).

[12]. Murthykumar K, Rajasekar A, Kaarthikeyan G. Assessment of various treatment modalities for isolated gingival recession defect- A retrospective study. Int. j. res. pharm. sci. 2020;11: 3-7.

[13]. Sabarathinam J, Rajasekar A, Madhulaxmi M. Prevalence of Furcation Involvement Among Patients with Periodontitis: A Cross Sectional Study. Int. j. res. pharm. sci. 2020;11: 1483-7.

[14]. Rajeshwaran N, Rajasekar A. Prevalence of Angular Bone Defects in Chronic Periodontitis Patients with and without Systemic Diseases. Indian J. Forensic Med. Toxicol. 2020 Oct 1;14(4).

[15]. Evaluation of Antiplaque and Antigingivitis Effects of A Herbal Mouthwash. Int. J. Pharm. Res. 2021;13.

[16]. Karde PA, Sethi KS, Mahale SA, Mamajiwala AS, Kale AM, Joshi CP. Comparative evaluation of two antibacterial-coated resorbable sutures versus noncoated resorbable sutures in periodontal flap surgery: A clinico-microbiological study. J Indian Soc Periodontol. 2019 May-Jun;23(3):220-225. Pubmed PMID: 31143002.

[17]. Burkhardt R, Lang NP. Influence of suturing on wound healing. Periodontol 2000. 2015 Jun;68(1):270-81.

[18]. Galgut PN. Suturing techniques in periodontal surgery. Br. Dent. J.1989 Jul;167(1):29-31. 
[19]. Khurana JV, Mali AM, Mali RS, Chaudhari AU. Comparative evaluation of healing after periodontal flap surgery using isoamyl 2-cyanoacrylate (bioadhesive material) and silk sutures: A split-mouth clinical study. J Indian Soc Periodontol. 2016 Jul-Aug;20(4):417-422.Pubmed PMID: 28298824.

[20]. Garg AK. Wound Healing and Suturing Techniques in Dental Implant Surgery. Implant Dent. 2010. p. 103-11.

[21]. Vastani A, Maria A. Healing of intraoral wounds closed using silk sutures and isoamyl 2-cyanoacrylate glue: a comparative clinical and histologic study. J Oral Maxillofac Surg. 2013 Feb;71(2):241-8.Pubmed PMID: 23089654.

[22]. Tryfonos O. Criteria to evaluate early wound healing in periodontal and implant surgery in humans: A Systematic Review.

[23]. Zuhr O, Akakpo DL, Hürzeler M. Wound closure and wound healing. Suture techniques in contemporary periodontal and implant surgery: Interactions, requirements, and practical considerations. Quintessence Int. $2017 \mathrm{Jul}$ 20:647-660.Pubmed PMID: 28740974.

[24]. Cohen ES. Atlas of cosmetic and reconstructive periodontal surgery. PMPHUSA; 2007:457.

[25]. Silverstein LH. Principles of dental suturing: the complete guide to surgical closure. Montage Media Corporation; 1999:80.

[26]. Ramesh A, Varghese S, Jayakumar ND, Malaiappan S. Comparative estimation of sulfiredoxin levels between chronic periodontitis and healthy patients - A case-control study. J Periodontol. 2018 Oct;89(10):1241-1248.Pubmed PMID: 30044495.

[27]. Paramasivam A, Priyadharsini JV, Raghunandhakumar S, Elumalai P. A novel COVID-19 and its effects on cardiovascular disease. Hypertens Res. $2020 \mathrm{Jul} ; 43(7): 729-30$.

[28]. S G, T G, K V, Faleh A A, Sukumaran A, P N S. Development of 3D scaffolds using nanochitosan/silk-fibroin/hyaluronic acid biomaterials for tissue engineering applications. Int J Biol Macromol. 2018 Dec;120(Pt A):876885.Pubmed PMID: 30171951.

[29]. Del Fabbro M, Karanxha L, Panda S, Bucchi C, Doraiswamy JN, Sankari $\mathrm{M}$, et al. Autologous platelet concentrates for treating periodontal infrabony defects. Cochrane Database Syst. Rev. 2018;11:CD011423.

[30]. Paramasivam A, Vijayashree Priyadharsini J. MitomiRs: new emerging microRNAs in mitochondrial dysfunction and cardiovascular disease. Hypertens Res. 2020 Aug;43(8):851-853.Pubmed PMID: 32152483.

[31]. Jayaseelan VP, Arumugam P. Dissecting the theranostic potential of exosomes in autoimmune disorders. Cell Mol Immunol. 2019 Dec;16(12):935-936. Pubmed PMID: 31619771.

[32]. Vellappally S, Al Kheraif AA, Divakar DD, Basavarajappa S, Anil S, Fouad $\mathrm{H}$. Tooth implant prosthesis using ultra low power and low cost crystalline carbon bio-tooth sensor with hybridized data acquisition algorithm. Comput Commun. 2019 Dec 15;148:176-84.

[33]. Vellappally S, Al Kheraif AA, Anil S, Assery MK, Kumar KA, Divakar DD. Analyzing Relationship between Patient and Doctor in Public Dental Health using Particle Memetic Multivariable Logistic Regression Analysis Approach (MLRA2). J Med Syst. 2018 Aug 29;42(10):183.Pubmed PMID: 30155746

[34]. Varghese SS, Ramesh A, Veeraiyan DN. Blended Module-Based Teaching in Biostatistics and Research Methodology: A Retrospective Study with Postgraduate Dental Students. J Dent Educ. 2019 Apr;83(4):445-450.Pubmed PMID: 30745352

[35]. Venkatesan J, Singh SK, Anil S, Kim SK, Shim MS. Preparation, Characterization and Biological Applications of Biosynthesized Silver Nanoparticles with Chitosan-Fucoidan Coating. Molecules. 2018 Jun 12;23(6):1429.Pubmed PMID: 29895803.

[36]. Alsubait SA, Al Ajlan R, Mitwalli H, Aburaisi N, Mahmood A, Muthurangan $\mathrm{M}$, et al. Cytotoxicity of different concentrations of three root canal sealers on human mesenchymal stem cells. Biomolecules. 2018 Sep;8(3):68.

[37]. Venkatesan J, Rekha PD, Anil S, Bhatnagar I, Sudha PN, Dechsakulwatana C, et al. Hydroxyapatite from cuttlefish bone: isolation, characterizations, and applications. Biotechnol Bioprocess Eng. 2018 Aug;23(4):383-93.

[38]. Vellappally S, Al Kheraif AA, Anil S, Wahba AA. IoT medical tooth mounted sensor for monitoring teeth and food level using bacterial optimization along with adaptive deep learning neural network. Measurement. 2019 Mar $1 ; 135: 672-7$.

[39]. PradeepKumar AR, Shemesh H, Nivedhitha MS, Hashir MMJ, Arockiam S, Uma Maheswari TN, et al. Diagnosis of Vertical Root Fractures by Conebeam Computed Tomography in Root-filled Teeth with Confirmation by Direct Visualization: A Systematic Review and Meta-Analysis. J Endod. 2021 Aug;47(8):1198-1214.Pubmed PMID: 33984375.

[40]. R H, Ramani P, Tilakaratne WM, Sukumaran G, Ramasubramanian A, Krishnan RP. Critical appraisal of different triggering pathways for the pathobiology of pemphigus vulgaris-A review. Oral Dis. 2021 Jun 21.Pubmed PMID: 34152662.

[41]. Ezhilarasan D, Lakshmi T, Subha M, Deepak Nallasamy V, Raghunandhakumar $S$. The ambiguous role of sirtuins in head and neck squamous cell carcinoma. Oral Dis. 2021 Feb 11.Pubmed PMID: 33570800.

[42]. Sarode SC, Gondivkar S, Sarode GS, Gadbail A, Yuwanati M. Hybrid oral potentially malignant disorder: A neglected fact in oral submucous fibrosis. Oral Oncol. 2021 Oct;121:105390.Pubmed PMID: 34147361.

[43]. Kavarthapu A, Gurumoorthy K. Linking chronic periodontitis and oral cancer: A review. Oral Oncol. 2021 Jun 16:105375

[44]. Vellappally S, Al-Kheraif AA, Anil S, Basavarajappa S, Hassanein AS. Maintaining patient oral health by using a xeno-genetic spiking neural network. J Ambient Intell Humaniz Comput. 2018 Dec 14:1-9.

[45]. Aldhuwayhi S, Mallineni SK, Sakhamuri S, Thakare AA, Mallineni S, Sajja R, et al. Covid-19 Knowledge and Perceptions Among Dental Specialists: A Cross-Sectional Online Questionnaire Survey. Risk Manag Healthc Policy. 2021 Jul 7;14:2851-2861.Pubmed PMID: 34262372.

[46]. WOUND HEALING. Wound Healing. 2005: 513.

[47]. Kumar K, Sharma RK, Tewari S, Narula SC. Use of modified vertical internal mattress suture versus simple loop interrupted suture in modified Widman flap surgery: a randomized clinical study. Quintessence Int. 2019;50(9):732740.Pubmed PMID: 31463484.

[48]. View of Modified vertical mattress suturing technique for flap approximation after ramping [Internet]. [cited 2021 Aug 30]. Available from:

[49]. Acar AH, Kazancioğlu HO, Erdem NF, Asutay F. Is Horizontal Mattress Suturing More Effective Than Simple Interrupted Suturing on Postoperative Complications and Primary Wound Healing After Impacted Mandibular Third Molar Surgery? J Craniofac Surg. 2017 Oct;28(7):e657-e661.Pubmed PMID: 28857982.

[50]. Tavelli L, Barootchi S, Ravidà A, Suárez-López Del Amo F, Rasperini G, Wang HL. Influence of suturing technique on marginal flap stability following coronally advanced flap: a cadaver study. Clin Oral Investig. 2019 Apr;23(4):1641-1651.Pubmed PMID: 30151706

[51]. Das R, Deshmukh J, Asif K, Sindhura H, Devarathanamma MV, Jyothi L. Comparative evaluation of analgesic and anti-inflammatory efficacy of ibuprofen and traumeel after periodontal flap surgery: A randomized tripleblind clinical trial. J Indian Soc Periodontol. 2019 Nov-Dec;23(6):549-553. Pubmed PMID: 31849401.

[52]. Nelson EH, Funakoshi E, O'Leary TJ. A comparison of the continuous and interrupted suturing techniques. J. Periodontol. 1977 May 1;48(5):273-81.

[53]. Burkhardt R, Joss A, Lang NP. Soft tissue dehiscence coverage around endosseous implants: a prospective cohort study. Clin. Oral Implants Res. 2008 May;19(5):451-7.

[54]. Burkhardt R, Lang NP. Role of flap tension in primary wound closure of mucoperiosteal flaps: a prospective cohort study. Clin Oral Implants Res. 2010 Jan;21(1):50-4.Pubmed PMID: 20070747.

[55]. Atterbury RA, Vazirani SJ. Removal of sutures following oral surgery. Oral Surg Oral Med Oral Pathol. 1961 Jun 1;14(6):658-61.

[56]. Tatakis DN, Chambrone L. The Effect of Suturing Protocols on Coronally Advanced Flap Root-Coverage Outcomes: A Meta-Analysis. J Periodontol. 2016 Feb;87(2):148-55.Pubmed PMID: 26447751.

[57]. Ho CCK, Attia D, Liu J. Suturing Techniques. Practical Procedures in Implant Dentistry. 2021: 155-62. 